\title{
Determination of 3,4-methylenedioxymethamphetamine (MDMA) in Confiscated Tablets by High-Performance Liquid Chromatography (HPLC) with Diode Array Detector
}

Natalia Biziak de Figueiredo ${ }^{1}$, Érica Naomi Oiye ${ }^{1}$, Matheus Manoel Teles de Menezes ${ }^{1}$, José Fernando de Andrade ${ }^{1}$, Maria Cristina Brunin Silva $^{2}$ and Marcelo Firmino de Oliveira ${ }^{1 *}$

${ }^{1}$ USP - Faculdade de Filosofia, Ciências e Letras de Ribeirão Preto - Departamento de Química - 14040-901-Ribeirão Preto, São Paulo, Brazil ${ }^{2}$ SPTC - Núcleo de Perícias Criminalísticas de Ribeirão Preto - 14015-040 - Ribeirão Preto, São Paulo, Brazil

\begin{abstract}
Chromatographic analysis by the HPLC technique with Diode Array Detector was employed for MDMA determination. A mobile phase of methanol/water (90:10v/v) allowed a peak signal for MDMA in 16 minutes. Optimized spectrophotometric signal was obtained at a wavelength of $240 \mathrm{~nm}$. The analytical curve from 5.0 to $100.0 \mathrm{ppm}$ of MDMA was obtained, showing a linear correlation coefficient of 0.9997 and a detection limit of $2.94 \mathrm{ppm}$. This methodology was employed at the dosage of confiscated samples of ecstasy in the Scientific Police Laboratory of Ribeirão Preto-SP city.
\end{abstract}

Keywords: MDMA; Ecstasy; HPLC; Criminalistics; Forensic chemistry Introduction

Amphetamine and amphetamine analogues have become an important psychotropic drug class with stimulant properties. The best known substance in this group is 3,4-methylenedioxymethamphetamine (MDMA), which is popularly called ecstasy, an illicit substance in several countries worldwide.

Ecstasy has easily become a widespread recreational drug due to its stimulant effects on the central nervous system (CNS) and increased sense of well being [1]. This type of drug is capable of suppressing tiredness or hunger because it blocks serotonine, dopamine and noradrenaline reabsorption in the brain [1].

The relative simple synthesis of various types of amphetamine and the possibility of altering this structures (Figure 1) by substituting the aromatic ring without significant changes in their potency [2] has contributed to its dissemination around the world, too. Furthermore, ecstasy can be sold at lower prices because it can be prepared from many natural products, such as safrole, iso-safrole, and piperonal [3].

In the illicit market, ecstasy is commonly sold as tablets containing between 50 and 150mg of MDMA [4]. In order to increase income and gain, many times the drug dealers commercialize adrenaline or simply MDA as ecstasy $[5,6]$.

Due to its robustness and low detection limits, the chromatographic analysis of MDMA in confiscated tablets has been carried out in several forensic laboratories around the world [3,7-9]. However, nowadays the major application of instrumental chromatographic techniques (HPLC and GC) consists in the research of MDMA and its metabolites in biological samples, such as hair [10,11], blood and plasma [12-16], and urine [17-20]. In terms of routine analysis in the police laboratories, instrumental chromatographic and spectrometric techniques figure as the most employed for the forensic analysis of drugs [21]. However, these systems are still not available in all police laboratories.

In this sense, the purpose of this study was to investigate a chromatographic methodology for ecstasy analysis in confiscated tablets by High-Performance Liquid Chromatography (HPLC), in order to verify its applicability in routine analysis accomplished in the Scientific Police Laboratory of the city of Ribeirão Preto -São Paulo, Brazil, and also in order to improve a partnership between the police institution and university.

\section{Experimental}

\section{Reagents and solutions}

Methanol from Merck (HPLC grade) and analytical standard MDMA from Cerrilliant (1000ppm in methanol) were employed in this work. Deionized water was obtained from a Milli-Q Water System (Millipore, CA, USA).

The confiscated samples of ecstasy were manipulated under supervision of the Institute of Criminalistics - city of Ribeirão Preto, state of São Paulo - Brazil.

The solutions used for construction of the analytical curve were obtained by dilution of $1 \mathrm{~mL}$ analytical standard MDMA $1000 \mathrm{ppm}$ in methanol. Six standard solutions with MDMA concentrations of 5.0, $10.0,20.0,30.0,50.0$ and $100.0 \mathrm{ppm}$, were obtained.

\section{Instruments}

A Shimadzu HPLC equipped with a Shimadzu SPDM-10AVP Diode Array Detector linked to a data system (Class VP) was used to determine MDMA in seized ecstasy tablets. An injection valve of Reodyne with a $20 \mu \mathrm{L}$ sample loop was employed.

Chromatographic determination of MDMA was achieved using a Shimadzu ODS column (C18, 250mm x 4.6mm i.d., $5 \mu \mathrm{m})$.

\section{HPLC analysis}

The mobile phase was a mixture of methanol and deionized water $(90: 10 \mathrm{v} / \mathrm{v})$. The flow rate was kept at $1.0 \mathrm{~mL} \mathrm{~min}^{-1}$ at a pressure

*Corresponding author: Marcelo Firmino de Oliveira, USP - Faculdade de Filosofia Ciências e Letras de Ribeirão Preto - Departamento de Química - 14040-901-Ribeirão Preto, São Paulo, Brazil, Tel: 55-16-3602-3750; E-mail: marcelex@ffclrp.usp.br

Received November 27, 2010; Accepted December 28, 2010; Published December 30, 2010

Citation: de Figueiredo NB, Oiye ÉN, de Menezes MMT, de Andrade JF, Brunin Silva MC, et al. (2010) Determination of 3,4-methylenedioxymethamphetamine (MDMA) in Confiscated Tablets by High-Performance Liquid Chromatography (HPLC) with Diode Array Detector. J Forensic Res 1:106. doi:10.4172/21577145.1000106

Copyright: (C) 2010 de Figueiredo NB, et al. This is an open-access article distributed under the terms of the Creative Commons Attribution License, which permits unrestricted use, distribution, and reproduction in any medium, provided the original author and source are credited. 
Citation:deFigueiredoNB, OiyeÉN, deMenezesMMT,deAndradeJF,BruniniSilvaMC,etal.(2010)Determinationof3,4-methylenedioxymethamphetamine (MDMA) in Confiscated Tablets by High-Performance Liquid Chromatography (HPLC) with Diode Array Detector. J Forensic Res 1:106. doi:10.4172/2157-7145.1000106

Page 2 of 3

of $131 \mathrm{kgf} \mathrm{cm}^{-2}$. MDMA determination was carried out at ambient temperature $\left(24^{\circ} \mathrm{C}\right)$, and the monitoring wavelength was $240 \mathrm{~nm}$, in order to produce optimized MDMA detection and prevent detection of amphetamine and metamphetamine [7]. Standard and sample solutions were injected into the equipment by a $20 \mathrm{~mL}$ sample loop employed at the injector-comutator system. All measurements were obtained in triplicate.

\section{Preparation of MDMA samples}

Eight samples of ecstasy tablets, which were confiscated by the local police in different events and periods during the year of 2009, with different colors (blue, green, red, and yellow) were employed in this study. Each ecstasy tablet was crushed to a fine powder in a porcelain mortar. Specific amounts of the powder sample from each tablet were directly dissolved in methanol, to a final volume of $10 \mathrm{~mL}$, and previously filtered before injection into the chromatograph.

\section{Validation}

Linearity was examined using standard MDMA alcoholic solution at concentrations of 5.0, 10.0, 20.0,30.0, 50.0, and $100.0 \mathrm{ppm}$.

The recovery tests were performed by successive injections of ecstasy sample solutions and the same solutions were spiked with MDMA 100 ppm standard solution.

\section{Results and Discussion}

The chromatograms obtained in this work indicated a retention time of 16.0 minutes for MDMA, exhibiting good resolution and lack of interfering effect from other substances in the samples, as observed in Figure 2.

The analytical curve for HPLC was based on the relation of the peak area and MDMA concentration in the standard solutions. The peak area was plotted against the concentration, and a linear range was obtained from 5.0 to $100.0 \mathrm{ppm}$ (Figure 2-c). This curve presented

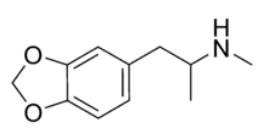

Figure 1: Chemical structure of MDMA

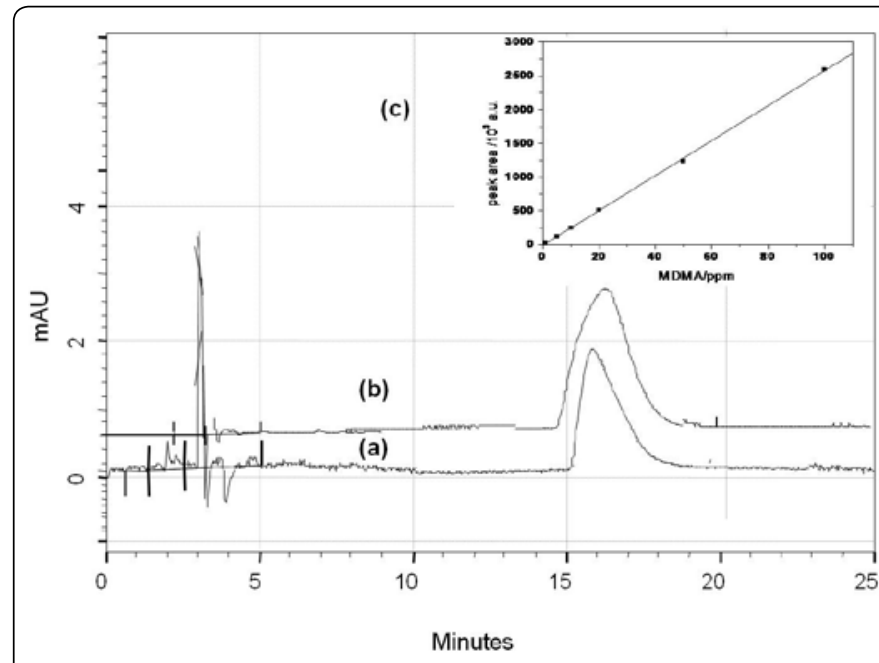

Figure 2: Chromatogram obtained for MDMA in a 90:10 (v/v) methanol/water solution. a) $56 \mathrm{ppm}$ ecstasy sample; b) $10 \mathrm{ppm}$ MDMA standard soution; c) analytical curve.

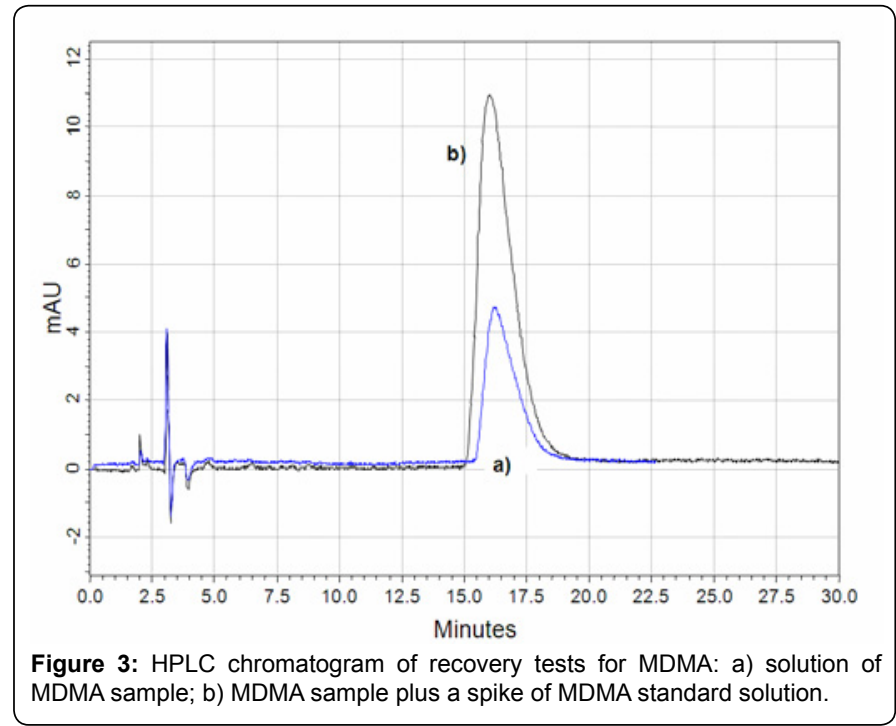

\begin{tabular}{|c|c|c|c|c|c|}
\hline Sample & $\begin{array}{c}\text { MDMA } \\
\text { expected } \\
\text { (ppm) }\end{array}$ & $\begin{array}{c}\text { MDMA } \\
\text { detected } \\
\text { (ppm) }\end{array}$ & SD & CV(\%) & $\begin{array}{c}\text { MDMA mass percentage in } \\
\text { the sample (\%) }\end{array}$ \\
\hline 1 & 31.0 & 6.5 & 0.35 & 5.4 & 21.0 \\
\hline 2 & 78.0 & 13.1 & 0.85 & 6.5 & 16.8 \\
\hline 3 & 68.0 & 19.5 & 0.84 & 4.3 & 28.7 \\
\hline 4 & 56.0 & 15.5 & 0.29 & 1.9 & 27.7 \\
\hline 5 & 85.0 & 16.6 & 0.12 & 0.7 & 19.5 \\
\hline 6 & 90.0 & 18.3 & 0.24 & 1.3 & 20.3 \\
\hline 7 & 75.1 & 15.6 & 0.50 & 3.2 & 20.8 \\
\hline 8 & 48.4 & 8.9 & 0.26 & 2.9 & 18.3 \\
\hline
\end{tabular}

Table 1: Chromatographic assay of ecstasy tablets. SD = standard deviation; $C V$ $=$ coefficient of variation.

a linear correlation coefficient of 0.9997 and a detection limit (LOD) of $2.94 \mathrm{ppm}$ was calculated as being $3 . \mathrm{SD} / \mathrm{m}$, with $\mathrm{m}$ being the slope of the analytical curve and SD its standard deviation [6].

The recovery studies furnished values situated between 94.9 $103.1 \%$ with coefficients of variation (C.V.) ranging from 0.7 to $6.5 \%$, thus indicating a good precision for MDMA determination in ecstasy seized tablets with good accuracy. A typical recovery test is reported at Figure 3.

According to the results obtained for the analysis of MDMA samples, each complete chromatogram can be obtained in 20 minutes without carryover effects. In this case, an analytical frequency of 3 analyses hour ${ }^{-1}$ (or 120 analyses week ${ }^{-1}$, considering only the commercial period of 8 hours and 5 days) is obtained for this technique. According to police information, the weekly incidence of ecstasy cases is lower than 15 samples; i.e., the proposed methodology can perfectly meet the local analysis demand. Additionally, the same equipment can promptly be employed for the development of analytical methods for the dosage of other drugs of forensic interest such as cocaine, crack and hemp.

On the basis of the results obtained from the analytical curve, it is possible to determine the percentage of MDMA in ecstasy tablets by analytical curve method. Results are reported in Table 1, where it is possible to observe that the MDMA level lies between 18 and $28 \%$ $(\mathrm{m} / \mathrm{m})$, even though samples from different events and periods of the year were tested. 
Citation:deFigueiredoNB, OiyeÉN, deMenezesMMT,deAndradeJF,BruniniSilvaMC,etal.(2010)Determinationof3,4-methylenedioxymethamphetamine (MDMA) in Confiscated Tablets by High-Performance Liquid Chromatography (HPLC) with Diode Array Detector. J Forensic Res 1:106. doi:10.4172/2157-7145.1000106

These results provide two important pieces of information for police investigation:

- The actual chemical profile of ecstasy tablets presents a large amount of adulterant substances (up to $70 \%$ ), which differs from the profile of the almost pure tablet samples (96-99.5\% of purity) usually apprehended in the beginning of this decade;

- The similar drift (18 - 28\%) observed for the samples suggests they have a possible common origin.

\section{Conclusion}

The analytical procedure for MDMA determination in seized ecstasy tablets by HPLC led to good repeatability and accuracy, without any elaborated pre-treatment.

According to the local laboratory of the Institute of Criminalistics, the forensic identification of illegal drugs by official agencies consists in at least two chemical tests - a presumptive and a final confirmatory test. The analytical frequency obtained for this technique strongly recommends this methodology, once it meets the local daily demand for ecstasy sample analysis. Therefore, this methodology can be used as a confirmatory instrumental test that can improve a rapid, simple, selective, sensitive and reproducible result for quantification and identification of MDMA in seixed ecstasy tablets.

\section{Acknowledgments}

We gratefully acknowledge the important contribution of Dra. Mércia Virginia Carlos (DQ-FFCLRP-USP) in the experimental analysis. Additionally, we acknowledge Fundação de Amparo à Pesquisa do Estado de São Paulo (FAPESP) and Conselho Nacional de Desenvolvimento Científico e Tecnológico (CNPq) for financial support.

\section{References}

1. Milhazes N, Martins P, Uriarte E, Garrido J, Calheiros R, et al. (2007) Electrochemical and spectroscopic characterization of amphetamina-like drugs: Application to the screening of 3,4-methylenedioxymethamphetamine (MDMA) and its synthetic precursors. Anal Chim Acta 596: 231-241.

2. Backofen U, Matysik FM, Hoffmann W, Lunte CE (2000) Analysis of illicit drugs by nonaqueous capillary electrophoresis and electrochemical detection. J Ana Chem 367: 359-363.

3. Makino Y, Tanaka S, Kurobane S, Nakauchi M, Terasaki T, et al. (2003) Profiling illegal amphetamine-type stimulant tablets in Japan. J Health Sci 49: 129-37.

4. Passagli M (2007) Toxicologia Forense: teoria e prática. Millenium, Brazil.

5. Butler D, Pravda M, Guilbault GG (2006) Development of a disposable amperometric immunosensor for the detection of ecstasy and its analogues using screen-printed electrodes. Anal Chim Acta 556: 333-39.

6. http://www.psicosite.com.br/tra/drg/ecstasy.htm. Accessed 25 Oct 2010.
7. Pastor D, Rica M, Sogo P, Gonzalez J (2003) Studies on "Ecstasy" and amphetamine seizures in Spain over 1995-2002 using GC-MS, HPLC, FTIR and XRD. Forensic Sci Int 136: 95.

8. Cheng WC, Poon NL, Chan MF (2003) Chemical profiling of 3,4-methylenedioxymethamphetamine (MDMA) tablets seized in Hong Kong J Forensic Sci 48:1249-1259.

9. Sadeghipour F, Varesio E, Giroud C, Rivier L, Veuthey JL (1997) Analysis of amphetamines by capillary electrophoresis and liquid chromatrography: application to drug seizures and cross-validation. Forensic Sci Int 86: 1-13.

10. Kaddoumi A, Kikura-Hanajiri R, Nakashima K (2004) High-performance liquid chromatography with fluorescence detection for the simultaneous determination of 3,4-methylenedioxymethamphetamine, methamphetamine and their metabolites in human hair using DIB-Cl as a label. Biomed Chromatogr 18: 202-204.

11. Nakamura S, Wada M, Crabtree BL, Reeves PM, Montgomery JH, et al (2007) A sensitive semi-micro column HPLC method with peroxyoxalate chemiluminescence detection and column switching for determination of MDMA-related compounds in hair. Anal Bioanal Chem 387: 1983-1990.

12. Tomita M, Nakashima MN, Wada M, Nakashima K (2007) Sensitive determination of MDMA and its metabolite MDA in rat blood and brain microdialysates by HPLC with fluorescence detection. Biomed Chromatogr 21: 1016-1022.

13. Michel RE, Rege AB, George WJ (1993) High-pressure liquid chro.matography/ electrochemical detection method for monitoring MDA and MDMA in wholeblood and other biological tissues. J Neurosci Methods 50: 61-66.

14. Clauwaert KM, Van Bocxlaer JF, De Letter A, Van Calenbergh $S$ Lambert WE, et al. (2000) Determination of the Designer Drugs 3,4-Methylenedioxymethamphetamine, 3,4 Methylenedioxyethylamphetamine and 3,4-Methylenedioxyamphetamine with HPLC and Fluorescence Detection in Whole Blood, Serum, Vitreous Humor, and Urine. Clinical Chem 46: 1968-77.

15. Kiss B, Popa DS, Lepure R, Bojit M, Loghin F (2008) Validation of a HPLCFLD/PDA method for the quantification of MDMA and MDA in human plasma. 180: S161.

16. Sadeghipour F, Veuthey JL (1998) Automated on-line dialysis and liquid chromatography of methylenedioxylated amphetamines in plasma and serum samples. J Pharm Biomed Anal 17: 801-810.

17. Concheiro M, Castro A, Quintela O, López-Rivadulla M, Cruz A (2005) Determination of MDMA, MDA, MDEA and MBDB in oral fluid using high performance liquid chromatography with native fluorescence detection. Forensic Sci Int 150: 221-226.

18. Soares ME, Carvalho M, Carmo H, Remião F, Carvalho F, et al. (2004) Simultaneous determination of amphetamine derivatives in human urine after SPE extraction and HPLC-UV analysis. Biomed Chromatogr 18: 125-131.

19. Talwar D, Watson ID, Stewart MJ (1999) Routine analysis of amphetamine class drugs as their naphthaquinone derivatives in human urine by highperformance liquid chromatography. J Chromatogr B 735: 229-41.

20. Helmlin HJ, Bracher K, Bourquin D, Vonlanthen D, Brenneisen R, et al. (1996) Analysis of 3,4-methylenedioxymethamphetamine (MDMA) and its metabolites in plasma and urine by HPLC-DAD and GC-MS. J Anal Toxic 20: 432-440.

21. Scientific working group for the analysis of seized drugs (SWGDRUG) recommendations. United States Department of Justice - Drug Enforcement Administration. $3^{\text {rd }}$ Ed 14-16 2007. 